\title{
Actinomycin C3
}

National Cancer Institute

\section{Source}

National Cancer Institute. Actinomycin C3. NCI Thesaurus. Code C99564.

A natural analogue of actinomycin, a chromopeptide antineoplastic antibiotic isolated from the bacterial genus Streptomyces. Actinomycin C3 inhibits DNA replication as well as RNA and protein synthesis by various mechanisms such as intercalating into the minor groove of DNA and interfering with the function of topoisomerase II. 